\title{
Birth weight and type 2 diabetes: A meta-analysis
}

\author{
DONGHUA MI ${ }^{1 *}$, HONGJUAN FANG $^{2 *}$, YAQUN ZHAO ${ }^{2}$ and LIYONG ZHONG ${ }^{2}$ \\ Departments of ${ }^{1}$ Neurology and ${ }^{2}$ Endocrinology, Beijing Tiantan Hospital, \\ Capital Medical University, Beijing 100050, P.R. China
}

Received December 28, 2016; Accepted July 7, 2017

DOI: $10.3892 /$ etm.2017.5234

\begin{abstract}
The prevalence of T2DM is increasing around the world on a yearly basis. A meta-analysis was conducted to analyze the association between birth weight and incidence of type 2 diabetes mellitus (T2DM). A literature search was performed from January 1990 to June 2016 in PubMed, ScienceDirect, SpringerLink, China National Knowledge Infrastructure and Chinese Biomedical Literature Database. After reviewing characteristics of all the included studies systematically, a meta-analytical method was employed to calculate the pooled odds ratios (ORs) and associated 95\% confidence intervals (CI) from random-effects models. Heterogeneity was assessed by Q-statistic test. Funnel plot, Begg's and Egger's linear regression tests were applied to evaluate publication bias. A sensitivity analysis was also performed to assess the robustness of results. According to inclusion and exclusion criteria, 8 studies were selected to be included in the meta-analysis. Compared with normal birth weight (2,500-4,000 g), low birth weight $(<2,500 \mathrm{~g})$ was associated with an increased risk of T2DM (OR, $1.55 ; 95 \%$ CI, 1.39-1.73; $\mathrm{P}<0.001)$. No significant difference was observed between high birth weight $(>4,000 \mathrm{~g})$ and normal birth weight in terms of the risk of T2DM (OR, 0.98; 95\% CI, 0.79-1.22). Compared with high birth weight, low birth weight was associated with an increased risk of diabetes mellitus (OR, 1.58; 95\% CI, 1.30-1.93; $\mathrm{P}<0.001)$. These findings indicated that there may be an inverse linear association between birth weight and T2DM.
\end{abstract}

\section{Introduction}

Type 2 diabetes mellitus (T2DM) is a common complex disease defined by hyperglycemia (1). The prevalence of T2DM is increasing year by year around the world and is becoming a serious global public health problem $(1,2)$. However, identifying the pathogenesis and mechanism is difficult due to

Correspondence to: Dr Liyong Zhong, Department of Endocrinology, Beijing Tiantan Hospital, Capital Medical University, 6 Tiantan Xili, Beijing 100050, P.R. China

E-mail: zhongliyong@126.com

"Contributed equally

Key words: birth weight, type 2 diabetes, meta-analysis heterogeneous phenotypes and a broad spectrum of pathophysiological processes (3). A previous study indicated that genetic variation and various postnatal factors (including smoking, physical activity and education) are associated with T2DM (4). However, A recent study reported that low birth weight, which reflects the intrauterine nutrient conditions, was associated with metabolic disorders after birth, such as obesity and insulin resistance (5). Low birth weight has also been demonstrated to be associated with adult cardiovascular disease and diabetes (6-10). The mechanism behind these associations is still unclear. One proposal is the fetal programming hypothesis: A lack of intrauterine nutrients causes a permanent metabolic shift towards insulin resistance to support brain glucose supply. After birth, the nutrient supply increases, which may lead to obesity and insulin resistance (5,11-15). An alternative proposal is the fetal insulin hypothesis, which suggests that common genetic variants decrease insulin secretion and cause low birth weight (16). The relationship between high birth weight and T2DM is not consistent. Some studies have demonstrated that birth weight is negatively associated with T2DM and high birth weight $(>4,000 \mathrm{~g})$ decreases the risk of T2DM (17-19). Other studies have reported that both high and low birth weight increase the risk of T2DM, and high birth weight is also a risk factor for T2DM (20-23).

In the present study, a meta-analysis was conducted in order to provide a comprehensive overview of the association between birth weight and T2DM.

\section{Materials and methods}

Search strategy. A literature search was conducted on PubMed (https://www.ncbi.nlm.nih.gov/pubmed), ScienceDirect (http://www.sciencedirect.com/), SpringerLink (https://link. springer.com/advanced-search), China National Knowledge Infrastructure (http://www.wanfangdata. com.cn/) and Chinese Biomedical Literature Database (http://www. sinomed.ac.cn/zh/) from January 1990 to June 2016 for relevant papers using the following terms: 'birth weight', 'type 2 diabetes', 'non-insulin-dependent', 'NIDDM' and 'risk factor'. The articles were restricted to those written in English or Chinese. The reference lists of the retrieved articles were also manually reviewed to identify publications on the same topic.

Study selection. To qualify for the present meta-analysis, studies were required to meet the following criteria: i) Unrelated cohort study; ii) recruited sufficient dichotomous 


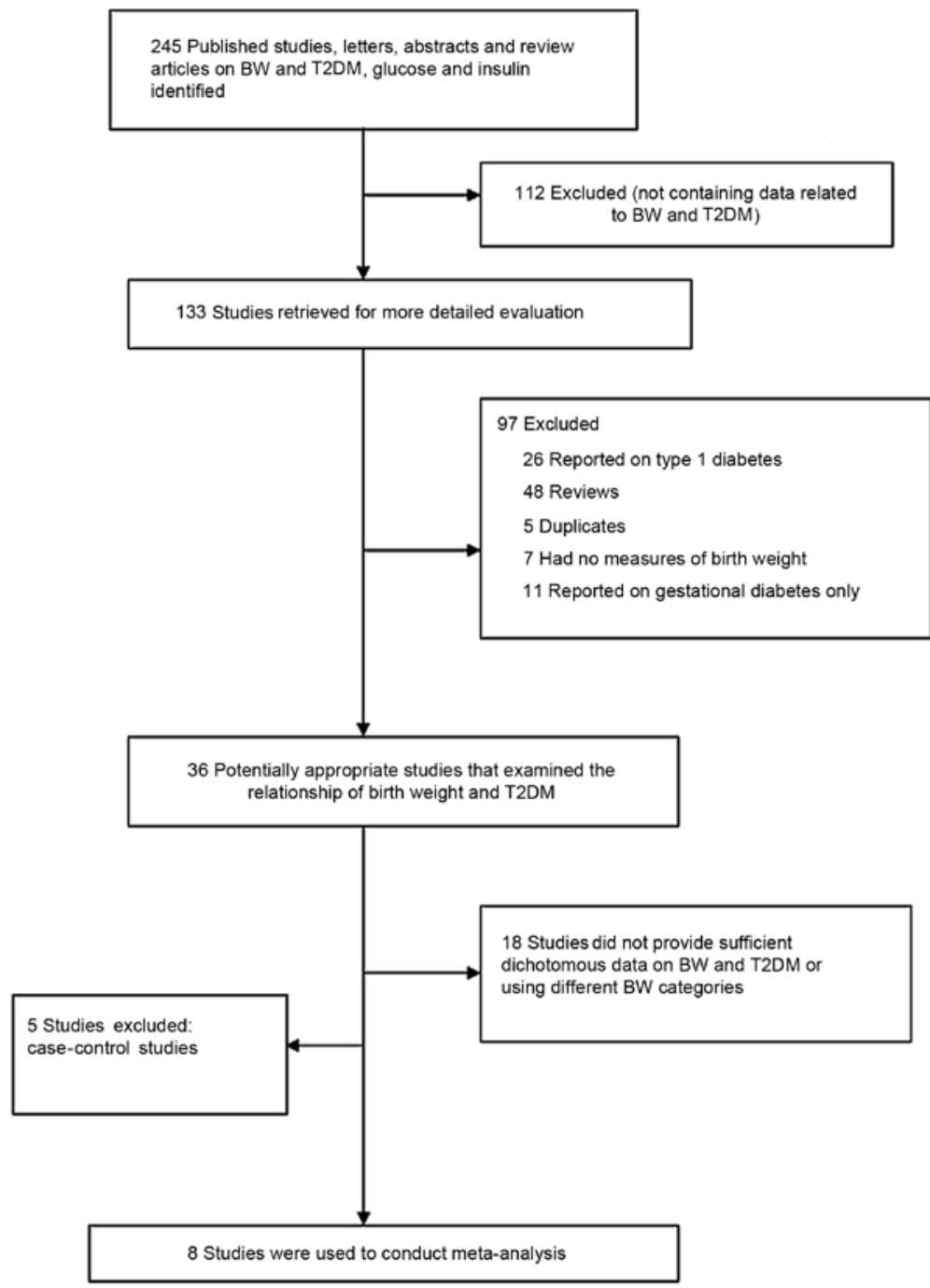

Figure 1. Summary of the article selection process. BW, birth weight; T2DM, type 2 diabetes mellitus.

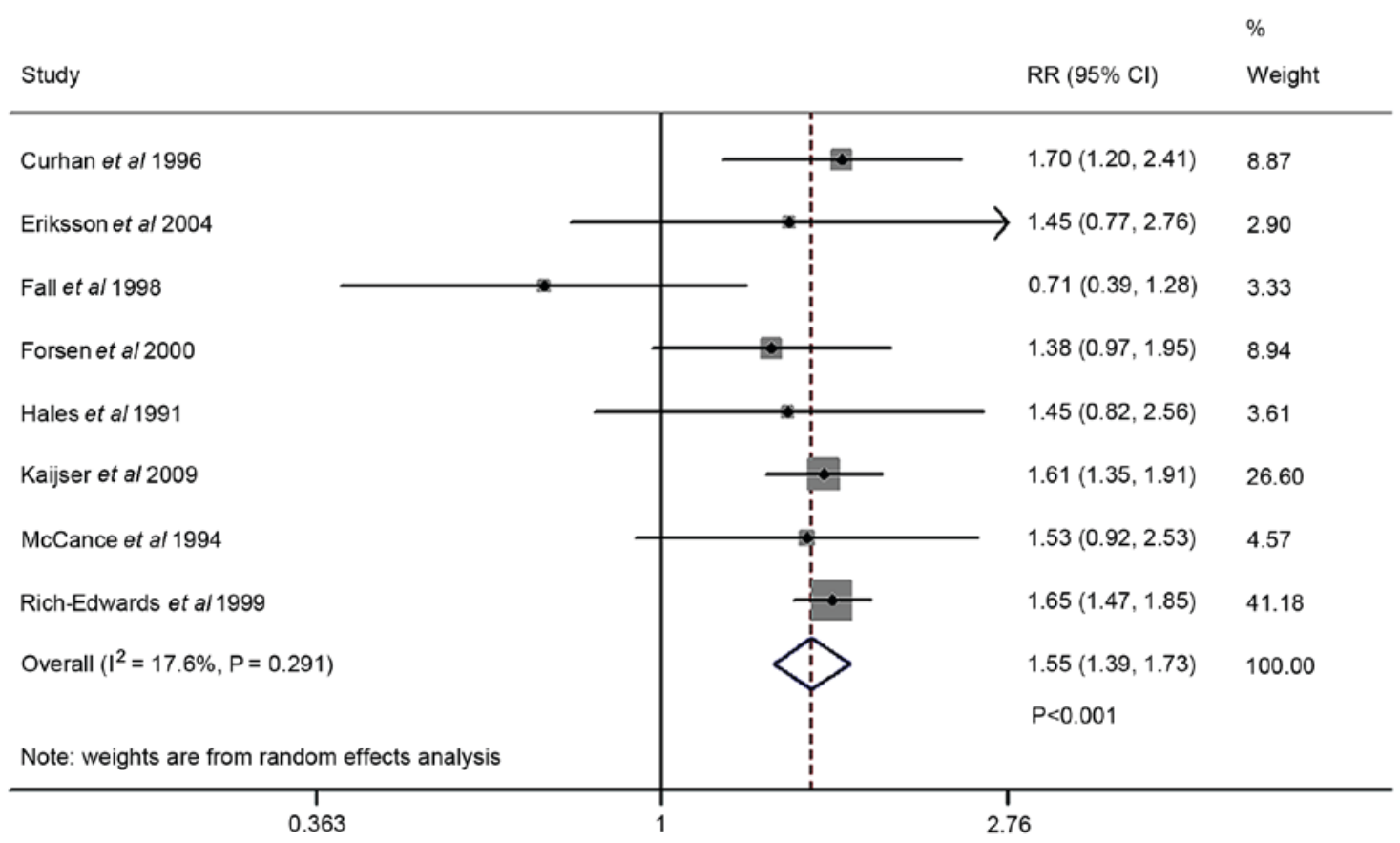

Figure 2. Forest plot comparing type 2 diabetes risk in low birth weight $(<2,500 \mathrm{~g})$ and normal birth weight subjects $(2,500-4,000 \mathrm{~g})$. The RR were calculated using a random-effects model. $95 \%$ CIs are indicated in parentheses and as horizontal bars. CI, confidence interval; RR, relative risk. 
data on T2DM and low birth weight; and iii) presented relative risk (RR) and $95 \%$ confidence intervals (CI), or data with which to calculate them, for T2DM in at least two strata of birth weight. Birth weight was required to be expressed in a specific range, such as $<2,500$ and $>2,500 \mathrm{~g}$, or $<4,000$ and $>4,000 \mathrm{~g}$. Alternatively, an RR and $95 \%$ CI for the change in $\mathrm{T} 2 \mathrm{DM}$ risk per unit change in birth weight could have been reported. Studies were considered irrespective of the definition of T2DM (definitions used included those of the World Health Organization (24), the National Diabetes Data Group (25) and the America Diabetes Association (26).

Data extraction. A standard extraction form was used to collect the following information from each study: First author name, year of publication, country in which the study was conducted, year of patient birth, patient age, trend declared by the study's authors, final cohort size and number of cases with T2DM. Data were extracted independently by two investigators. Discrepancies, if any, were resolved by discussion and consultation with a third reviewer.

Quality assessment. Two investigators performed a quality assessment using the Newcastle-Ottawa scale (27) for included studies. This scale allocates a maximum of nine stars for the highest quality of selection, comparability and ascertainment of exposure to risks. The four criteria in evaluating the selection were as follows: i) Representativeness of the low birth weight; ii) selection of the non-low birth weight; iii) ascertainment of low birth weight; and iv) demonstration that T2DM was not present at the start of the study. A maximum of two stars was awarded for comparability: i) Study controls for age; and ii) study controls for any additional factors. The three criteria in evaluating the outcomes were as follows: i) Assessment of T2DM; ii) follow-up was long enough for T2DM to occur (>10 years); and iii) adequacy of follow-up of cohort $(>80 \%)$. The two authors discussed the implementation of this assessment tool and agreed on a method of implementation prior to their independent assessment of studies.

Statistical analysis. Meta-analysis was conducted using Review Manager (version 5.1; The Nordic Cochrane Centre, Copenhagen, Denmark). Measurement data were presented as the weighted mean difference and 95\% CI. Enumerated data were presented as the odds ratio (OR) and 95\% CI. Cochran's $\mathrm{Q}$ statistic and $\mathrm{I}^{2}$ statistic were used to assess heterogeneity. If significant heterogeneity was observed, the random-effects model was used. Otherwise, the fixed-effects model was used $(28,29) . \mathrm{P}<0.05$ was considered to indicate a statistically significant result.

Publication bias was assessed by inspection of a funnel plot and formal testing for funnel plot asymmetry was performed using Begg's test and Egger's test. Sensitivity analysis was performed by excluding one study at a time to identify the influence of individual data sets on the pooled RR.

\section{Results}

Preliminaryscreening of literature. A total of 245 studies related to birth weight and T2DM were identified during the literature

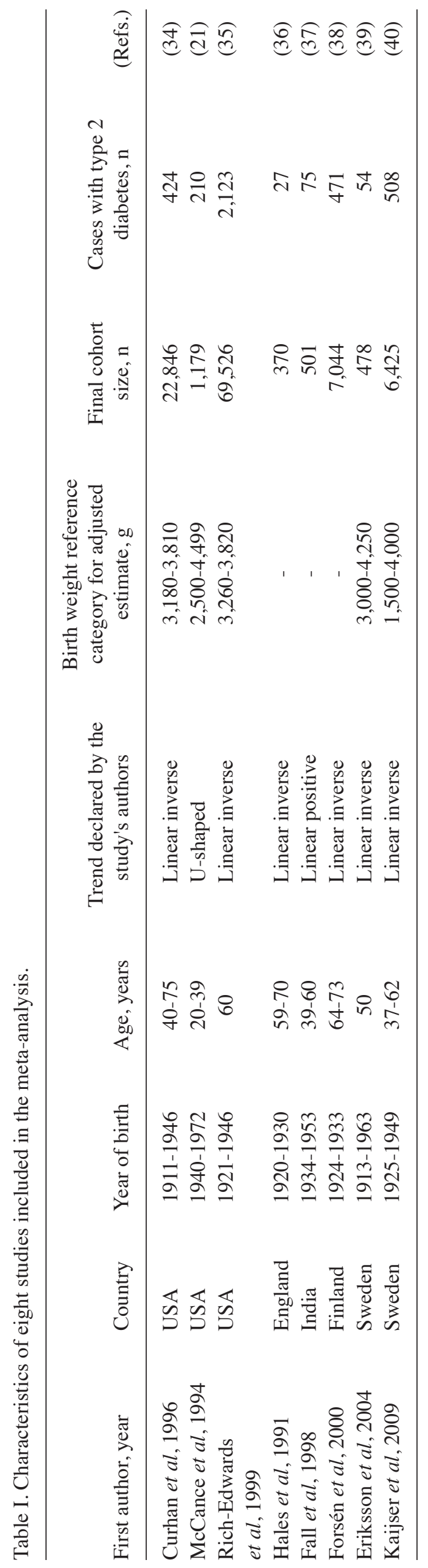


Table II. Assessment of study quality based on the Newcastle-Ottawa scale.

\begin{tabular}{|c|c|c|c|c|}
\hline First author, year & $\begin{array}{c}\text { Selection } \\
\text { (stars out of } 4 \text { ) }\end{array}$ & $\begin{array}{l}\text { Comparability } \\
\text { (stars out of 2) }\end{array}$ & $\begin{array}{c}\text { Exposure } \\
\text { (stars out of 3) }\end{array}$ & (Refs.) \\
\hline Curhan et al, 1996 & $\star \star \star$ & $\star$ & $\star \star$ & (34) \\
\hline McCance et al, 1994 & $\star \star \star$ & $\star \star$ & $\star \star$ & (21) \\
\hline Rich-Edwards et al, 1999 & $\star \star$ & $\star \star$ & $\star \star$ & (35) \\
\hline Hales et al, 1991 & $\star \star \star$ & $\star$ & $\star \star$ & (36) \\
\hline Fall et al, 1998 & $\star \star \star$ & $\star$ & $\star \star$ & (37) \\
\hline Forsen et al, 2000 & $\star \star \star$ & $\star$ & $\star \star$ & (38) \\
\hline Eriksson et al, 2004 & $\star \star \star \star$ & $\star \star$ & $\star \star \star$ & (39) \\
\hline Kaijser et al, 2009 & $\star \star \star$ & $\star$ & $\star \star$ & $(40)$ \\
\hline
\end{tabular}

Table III. Result of leave-one-out sensitivity analysis; low birth weight vs. normal birth weight).

\begin{tabular}{lrcc}
\hline First author, year & $\mathrm{I}^{2}(\%)$ & P-value & (Refs.) \\
\hline Curhan et al, 1996 & 28.0 & 0.215 & $(34)$ \\
McCance et al, 1994 & 29.2 & 0.206 & $(21)$ \\
Rich-Edwards et al, 1999 & 19.8 & 0.278 & $(35)$ \\
Hales et al, 1991 & 28.5 & 0.211 & $(36)$ \\
Fall et al, 1998 & 0.0 & 0.973 & $(37)$ \\
Forsen et al, 2000 & 23.5 & 0.250 & $(38)$ \\
Eriksson et al, 2004 & 28.7 & 0.209 & $(39)$ \\
Kaijser et al, 2009 & 29.0 & 0.207 & $(40)$ \\
\hline
\end{tabular}

Table IV. Result of leave-one-out sensitivity analysis; birth weight vs. normal birth weight).

\begin{tabular}{lccc}
\hline First author, year & $\mathrm{I}^{2}(\%)$ & P-value & (Refs.) \\
\hline Curhan et al, 1996 & 71.6 & 0.003 & $(34)$ \\
McCance et al, 1994 & 64.5 & 0.015 & $(21)$ \\
Rich-Edwards et al, 1999 & 63.0 & 0.019 & $(35)$ \\
Hales et al, 1991 & 56.3 & 0.043 & $(36)$ \\
Forsen et al, 2000 & 67.4 & 0.009 & $(38)$ \\
Eriksson et al, 2004 & 72.0 & 0.003 & $(39)$ \\
Kaijser et al, 2009 & 70.2 & 0.005 & $(40)$ \\
\hline
\end{tabular}

search. However, 237 studies were excluded for the following reasons: i) Did not contain birth weight and T2DM data $(n=112)$; ii) reported on type 1 diabetes $(n=26)$; iii) review articles $(n=48)$; iv) duplicates $(n=5)$; v) did not contain birth weight-related data $(n=7)$; vi) reported on gestational diabetes ( $n=11)$; vii) did not present binary data about birth weight and T2DM and did not use the indicated birth weight range $(n=18)$; viii) case-control studies $(n=5)(23,30-33)$. The remaining eight studies were selected in order to conduct the meta-analysis (Fig. 1) (21,34-40).
Table V. Result of leave-one-out sensitivity analysis; low birth weight vs. high birth weight.

\begin{tabular}{lccc}
\hline First author, year & $\mathrm{I}^{2}(\%)$ & P-value & $($ Refs.) \\
\hline Curhan et al, 1996 & 43.4 & 0.116 & $(34)$ \\
Eriksson et al, 2004 & 42.7 & 0.121 & $(39)$ \\
Forsen et al, 2000 & 45.3 & 0.104 & $(38)$ \\
Hales et al, 1991 & 22.5 & 0.265 & $(36)$ \\
Kaijser et al, 2009 & 35.4 & 0.171 & $(40)$ \\
McCance et al, 1994 & 24.2 & 0.253 & $(21)$ \\
Rich-Edwards et al, 1999 & 34.7 & 0.176 & $(35)$ \\
\hline
\end{tabular}

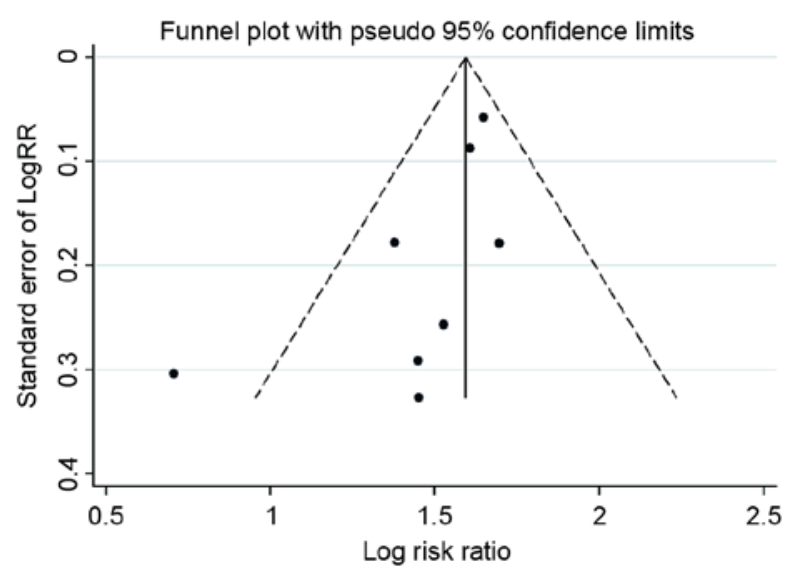

Figure 3. Funnel plot of studies evaluating the association between birth weight (low, $<2,500 \mathrm{~g}$ vs. normal, 2,500-4,000 g) and diabetes. RR, relative risk.

The eight included studies are presented in Table I. A total of 108,369 individuals were included in these studies and 3,892 were diagnosed with T2DM. All eight studies indicated the OR value of T2DM through comparing low birth weight $(<2,500 \mathrm{~g})$ and normal birth weight $(2,500-4,000 \mathrm{~g})$. Seven studies indicated the OR value of T2DM through comparing normal birth weight and high birth weight $(>4,000 \mathrm{~g})$. These seven studies also indicated the OR value through comparing 


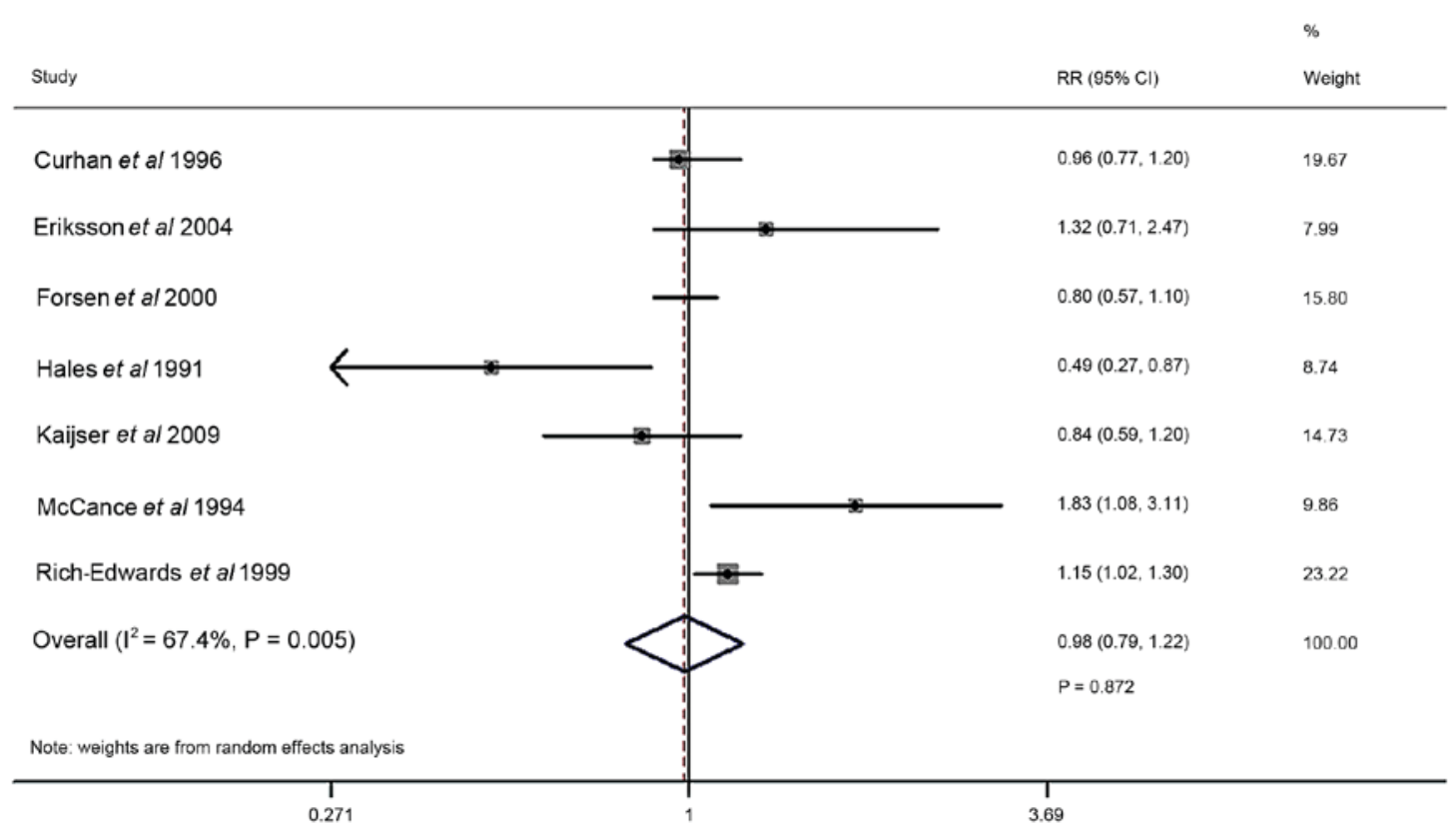

Figure 4. Forest plot comparing type 2 diabetes risk in high birth weight $(>4,000 \mathrm{~g})$ and normal birth weight subjects $(2,500-4,000 \mathrm{~g})$. The RR were calculated using a random-effects model. $95 \%$ CIs are indicated in parentheses and as horizontal bars. CI, confidence interval; RR, relative risk.

low birth weight and high birth weight. In one study, there was a U-shaped curve relationship between birth weight and T2DM. Furthermore, one study reported that birth weight was positively associated with T2DM. There was a linear inverse trend in 6 studies. According to the Newcastle-Ottawa scale, the mean score for the selection, comparability and exposure for the included studies was 6.5 stars (Table II).

Meta-analysis results. The forest plot comparing T2DM risk in cases of low birth weight and normal birth weight is presented in Fig. 2. The T2DM risk analysis was included in eight studies. Random-effects model assessment $\left(\mathrm{Q}^{2}=8.49\right.$; $\mathrm{P}=0.291 ; \mathrm{I}^{2}=17.6 \%$ ) indicated that low birth weight increased the risk of T2DM compared with normal birth weight $(\mathrm{OR}=1.55 ; 95 \% \mathrm{CI}, 1.39-1.73 ; \mathrm{P}<0.001)$. Sensitivity analysis indicated that the pooled ORs were no statistically significant no matter what study was excluded from analysis, suggesting the robustness of results. This analysis also revealed that one study, by Fall et al (37), was the largest source of heterogeneity (Table III). The $\mathrm{I}^{2}$ measure for low birth weight markedly declined from 17.6 to $0.0 \%$ when this study was omitted. Homogeneity was achieved after excluding Fall et al (37) $\left[Q=1.28\right.$; degrees of freedom $\left.(\mathrm{df})=6 ; \mathrm{P}=0.973 ; \mathrm{I}^{2}=0.00\right)$ and an RR of 1.62 was obtained (95\%CI, 1.478-1.754; fixed-effects; $\mathrm{P}<0.001$; data not shown). A funnel plot (Fig. 3) and Begg's and Egger's tests were conducted to assess the publication bias of the included studies. Evidence of publication bias was also not seen with the Egger's or Begg's tests (Egger's, $\mathrm{P}=0.103$; Begg's, $\mathrm{P}=0.083$; data not shown).

The forest plot of T2DM risk comparing high birth weight and normal birth weight is presented in Fig. 4. The risk analysis was conducted in 7 studies. Random-effects model assessment $\left(\mathrm{Q}^{2}=18.38 ; \mathrm{P}=0.005 ; \mathrm{I}^{2}=67.4 \%\right)$ indicated that there was no significant association between high birth weight and T2DM (OR=0.98; 95\% CI, 0.79-1.22; P=0.872). Sensitivity analysis revealed that one study by Hales et al (36) was the

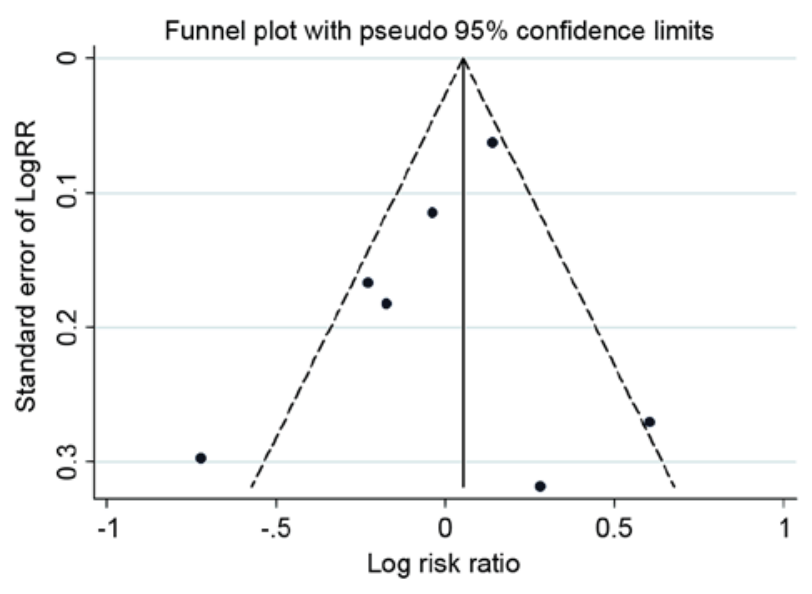

Figure 5. Funnel plot of studies evaluating the association between birth weight (high, >4,000 g vs. normal, 2,500-4,000 g) and diabetes. RR, relative risk.

largest source of heterogeneity (Table IV). The $\mathrm{I}^{2}$ measure for high birth weight markedly declined from 67.4 to $56.3 \%$ when this study was omitted. A funnel plot (Fig. 5) and Begg's and Egger's tests were conducted to assess the publication bias of the included studies. No evidence of publication bias was observed. Evidence of publication bias was also not observed with the Egger's or Begg's tests (Egger's, $\mathrm{P}=0.167$; Begg's, $\mathrm{P}=0.024$; data not shown).

The forest plot comparing T2DM risk in cases of low birth weight and high birth weight is presented in Fig. 6. The risk analysis was conducted in 7 studies. Random-effects model assessment $\left(\mathrm{Q}^{2}=9.45 ; \mathrm{P}=0.150 ; \mathrm{I}^{2}=36.5 \%\right)$ indicated that low birth rate was associated with a higher risk of T2DM compared with high birth weight (RR, 1.58; 95\% CI 1.30-1.93; $\mathrm{P}<0.001)$. Sensitivity analysis revealed that one study, by McCance et al (21), was the largest source of heterogeneity (Table V). The $\mathrm{I}^{2}$ measure for low birth weight markedly 


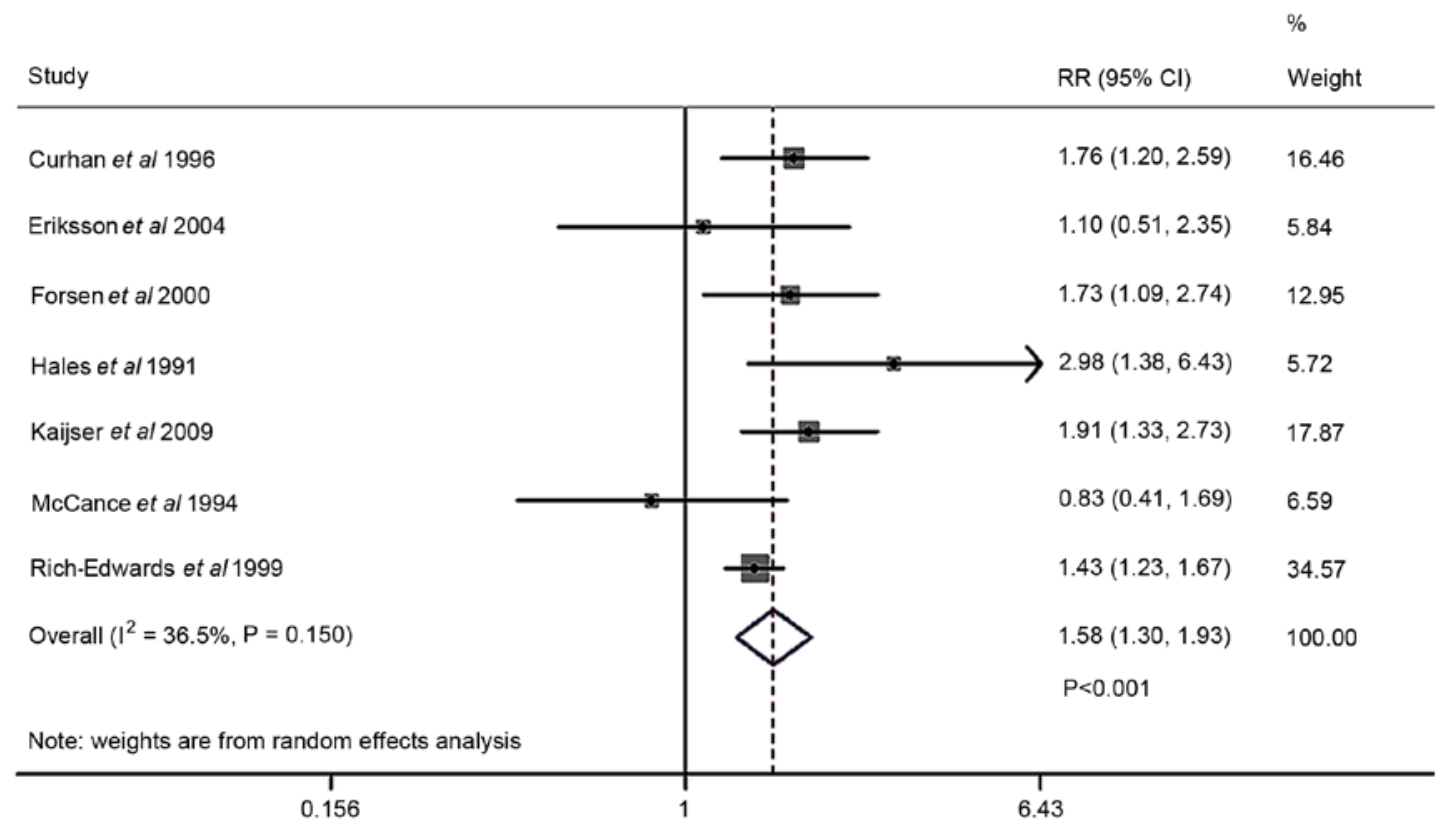

Figure 6. Forest plot comparing type 2 diabetes risk in low birth weight $(<2,500 \mathrm{~g})$ and high birth weight subjects $(>4,000 \mathrm{~g})$. The RR were calculated using a random-effects model. $95 \%$ CIs are indicated in parentheses and as horizontal bars. CI, confidence interval; RR, relative risk.

declined from 36.5 to $24.2 \%$. Homogeneity was achieved after excluding a study $\left(\mathrm{Q}=6.59 ; \mathrm{df}=5 ; \mathrm{P}=0.253 ; \mathrm{I}^{2}=24.2 \%\right)$, and an OR of 1.63 was obtained (95\% CI, 1.367-1.937; fixed-effects; $\mathrm{P}<0.001$ ). A funnel plot (Fig. 7) and Begg's and Egger's tests were conducted to assess the publication bias of the included studies. Evidence of publication bias was also not observed with the Egger's or Begg's tests (Egger's, P=0.663; Begg's. $\mathrm{P}=0.881$; data not shown).

\section{Discussion}

Previous studies have demonstrated that birth weight is associated with chronic diseases, including obesity (41), cardiovascular disease (42) and hypertension (43). However, the association between birth weight and T2DM is still unclear. Some studies have demonstrated a U-shaped curve relationship between them (20-22), while other studies have indicated a negative linear association (18,44-46). In the present study, a meta-analysis of the published literature was conducted, which studied the association between birth weight and T2DM. A total of eight studies were selected for analysis. Forest plots were constructed comparing T2DM risk in cases of low and normal birth weight, high and normal birth weight, and low and high birth weight, respectively. The analysis indicated that low birth weight increased the risk of T2DM and high birth weight had no notable influence on the risk of T2DM.

The studies indicated that low birth weight was related to T2DM; however, the mechanism by which low birth weight increases the risk of T2DM remains unclear (47-52). Some research has suggested that it may be a compensatory adaptation to an adverse intrauterine environment during fetal development. The smaller fetus and structural and functional change of important organs leads to insulin resistance and abnormal islet development, which could cause diabetes in adults (53). A lack of nutrients may have a permanent influence

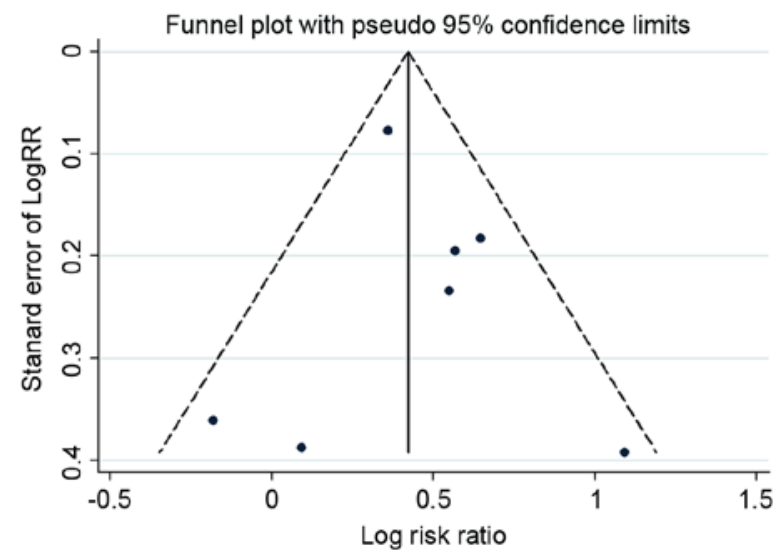

Figure 7. Funnel plot of studies evaluating the association between birth weight (low, $<2,500 \mathrm{~g}$ vs. high, $>4,000 \mathrm{~g}$ ) and diabetes. RR, relative risk

on the fetal metabolism, increasing the risk of obesity and T2DM in adults (54).

Some studies employed ${ }^{31} \mathrm{P}$ magnetic resonance spectroscopy and identified that glycolysis was decreased in cases of low birth weight. The adipose tissue in muscles also was decreased in these cases $(55,56)$. Indirect calorimetry or carbohydrate metabolism efficiency using ${ }^{13} \mathrm{C}$ indicated that the oxidation ability of postprandial glucose was decreased in cases of low birth weight (57). These studies are instrumental to understanding a possible mechanism between low birth weight and T2DM.

Poor intrauterine nutrition leads to low birth weight (58). For a fetus with low birth weight, leptin level was increased during childhood and adiponectin level was also positively related to birth weight, which increased the incidence rate of T2DM (59). This suggests that low birth weight may be a clinical marker of poor intrauterine environment and a potential risk factor for T2DM. 
The present study has several limitations that require further consideration. Due to limited data, it was not possible to perform further stratification analyses of other potential influencing factors, including gender.

In conclusion, the current meta-analysis demonstrated that low birth weight increases the risk of T2DM. Low birth weight may be a potential risk factor and marker for T2DM. Further research is required to elucidate the etiopathogenic mechanisms behind this association.

\section{Acknowledgements}

The present study was funded by the Beijing Talents Fund (grant no. 2015000021469G220), the National Natural Science Foundation of China (grant no. 8160105) and the Beijing Municipal Administration of Hospitals' Youth Programme (grant no. QML20160501).

\section{References}

1. Wild S, Roglic G, Green A, Sicree R and King H: Global prevalence of diabetes: Estimates for the year 2000 and projections for 2030. Diabetes care 27: 1047-1053, 2004

2. Zimmet P: Globalization, coca-colonization and the chronic disease epidemic: Can the Doomsday scenario be averted? J Intern Med 247: 301-310, 2000

3. Beaumont RN, Horikoshi M, McCarthy MI and Freathy RM: How can genetic studies help us to understand links between birth weight and Type 2 diabetes? Curr Diab Rep 17: 22, 2017.

4. Andersen MK, Pedersen CE, Moltke I, Hansen T, Albrechtsen A and Grarup N: Genetics of Type 2 diabetes: The power of isolated populations. Curr Diab Rep 16: 65, 2016.

5. Vejrazkova D, Lukasova P, Vankova M, Bradnova O Vacinova G, Vcelak J, Cirmanova V, Andelova K, Krejci H and Bendlova B: Gestational diabetes-metabolic risks of adult women with respect to birth weight. Physiol Res 64 (Suppl 2): S135-S145, 2015.

6. Stansfield BK, Fain ME, Bhatia J, Gutin B, Nguyen JT and Pollock NK: Nonlinear relationship between birth weight and visceral fat in adolescents. J Pediatr 174: 185-192, 2016.

7. Barker DJ, Hales CN, Fall CH, Osmond C, Phipps $\mathrm{K}$ and Clark PM: Type 2 (non-insulin-dependent) diabetes mellitus, hypertension and hyperlipidaemia (syndrome X): Relation to reduced fetal growth. Diabetologia 36: 62-67, 1993.

8. Brons C, Jacobsen S, Hiscock N, White A, Nilsson E, Dunger D, Astrup A, Quistorff B and Vaag A: Effects of high-fat overfeeding on mitochondrial function, glucose and fat metabolism, and adipokine levels in low-birth-weight subjects. Am J Physiol Endocrinol Metab 302: E43-E51, 2012.

9. Kahn HS, Graff M, Stein AD and Lumey LH: A fingerprint marker from early gestation associated with diabetes in middle age: The Dutch hunger winter families study. Int J Epidemiol 38: 101-109, 2009.

10. Norris SA, Osmond C, Gigante D, Kuzawa CW, Ramakrishnan L, Lee NR, Ramirez-Zea M, Richter LM, Stein AD, Tandon N, et al: Size at birth, weight gain in infancy and childhood, and adult diabetes risk in five low- or middle-income country birth cohorts. Diabetes care 35: 72-79, 2012.

11. Ong KK and Dunger DB: Thrifty genotypes and phenotypes in the pathogenesis of type 2 diabetes mellitus. J Pediatr Endocrinol Metab 13 (Suppl 6): S1419-S1424, 2000.

12. Ong KK, Ahmed ML, Emmett PM, Preece MA and Dunger DB: Association between postnatal catch-up growth and obesity in childhood: Prospective cohort study. BMJ (Clinical research ed) 320: 967-971, 2000.

13. Yajnik C: Interactions of perturbations in intrauterine growth and growth during childhood on the risk of adult-onset disease. Proc Nutr Soc 59: 257-265, 2000.

14. Stettler N, Bovet P, Shamlaye H, Zemel BS, Stallings VA and Paccaud F: Prevalence and risk factors for overweight and obesity in children from Seychelles, a country in rapid transition: The importance of early growth. Int J Obes Relat Metab Disord 26: 214-219, 2002.
15. Durmus B, Mook-Kanamori DO, Holzhauer S, Hofman A, van der Beek EM, Boehm G, Steegers EA and Jaddoe VW: Growth in foetal life and infancy is associated with abdominal adiposity at the age of 2 years: The generation $\mathrm{R}$ study. Clin Endocrinol (Oxf) 72: 633-640, 2010.

16. Fowden AL and Forhead AJ: Endocrine interactions in the control of fetal growth. Nestle Nutr Inst Workshop Ser 74: 91-102, 2013.

17. Hales CN: Non-insulin-dependent diabetes mellitus. Br Med Bull 53: 109-122, 1997.

18. Godfrey KM and Barker DJ: Fetal nutrition and adult disease. Am J Clin Nutr 71 (5 Suppl): 1344S-1352S, 2000.

19. Whincup PH, Kaye SJ, Owen CG, Huxley R, Cook DG, Anazawa S, Barrett-Connor E, Bhargava SK, Birgisdottir BE, Carlsson S, et al: Birth weight and risk of type 2 diabetes: A systematic review. Jama 300: 2886-2897, 2008.

20. Dyck RF, Klomp H and Tan L: From 'thrifty genotype' to 'hefty fetal phenotype': The relationship between high birth weight and diabetes in Saskatchewan registered Indians. Can J Public Health 92: 340-344, 2001

21. McCance DR, Pettitt DJ, Hanson RL, Jacobsson LT, Knowler WC and Bennett PH: Birth weight and non-insulin dependent diabetes: Thrifty genotype, thrifty phenotype, or surviving small baby genotype? BMJ (Clinical research ed) 308: 942-945, 1994.

22. Wei JN, Sung FC, Li CY, Chang CH, Lin RS, Lin CC, Chiang CC and Chuang LM: Low birth weight and high birth weight infants are both at an increased risk to have type 2 diabetes among school children in taiwan. Diabetes care 26: 343-348, 2003.

23. Harder T, Rodekamp E, Schellong K, Dudenhausen JW and Plagemann A: Birth weight and subsequent risk of type 2 diabetes: A meta-analysis. Am J Epidemiol 165: 849-857, 2007.

24. Alberti KG and Zimmet PZ: Definition, diagnosis and classification of diabetes mellitus and its complications. Part 1: Diagnosis and classification of diabetes mellitus provisional report of a WHO consultation. Diabet Med 15: 539-553, 1998.

25. Classification and diagnosis of diabetes mellitus and other categories of glucose intolerance. National diabetes data group. Diabetes 28: 1039-1057, 1979.

26. American Diabetes Association: Diagnosis and classification of diabetes mellitus. Diabetes Care 35 (Suppl 1): S64-S71, 2012.

27. Wells GA, Shea BJ, O'Connell D, Peterson J, Welch V, Losos M and Tugwell P: The Newcastle-Ottawa Scale (NOS) for assessing the quality of non-randomized studies in meta-analysis. Ottawa Hospital Research Institute, Ottawa, ON, USA, 2009. http://www. ohri.ca/programs/clinical_epidemiology/oxford.asp. Accessed February 1, 2009.

28. Higgins JP, Thompson SG, Deeks JJ and Altman DG: Measuring inconsistency in meta-analyses. BMJ (Clinical research ed) 327 : 557-560, 2003.

29. Begg CB and Mazumdar M: Operating characteristics of a rank correlation test for publication bias. Biometrics 50: 1088-1101, 1994.

30. Eriksson JG, Forsen T, Tuomilehto J, Osmond C and Barker DJ: Early adiposity rebound in childhood and risk of Type 2 diabetes in adult life. Diabetologia 46: 190-194, 2003.

31. Barker DJ, Eriksson JG, Forsen T and Osmond C: Fetal origins of adult disease: Strength of effects and biological basis. Int J Epidemiol 31: 1235-1239, 2002.

32. Young TK, Martens PJ, Taback SP, Sellers EA, Dean HJ, Cheang $\mathrm{M}$ and Flett B: Type 2 diabetes mellitus in children: Prenatal and early infancy risk factors among native canadians. Arch Pediatr Adolesc Med 156: 651-655, 2002.

33. Jornayvaz FR, Vollenweider P, Bochud M, Mooser V, Waeber G and Marques-Vidal P: Low birth weight leads to obesity, diabetes and increased leptin levels in adults: The CoLaus study. Cardiovasc Diabetol 15: 73, 2016.

34. Curhan GC, Willett WC, Rimm EB, Spiegelman D, Ascherio AL and Stampfer MJ: Birth weight and adult hypertension, diabetes mellitus, and obesity in US men. Circulation 94: 3246-3250, 1996.

35. Rich-Edwards JW, Colditz GA, Stampfer MJ, Willett WC, Gillman MW, Hennekens CH, Speizer FE and Manson JE: Birth weight and the risk for type 2 diabetes mellitus in adult women. Ann Intern Med 130: 278-284, 1999.

36. Hales CN, Barker DJ, Clark PM, Cox LJ, Fall C, Osmond C and Winter PD: Fetal and infant growth and impaired glucose tolerance at age 64. BMJ (Clinical research ed) 303: 1019-1022, 1991.

37. Fall CH, Stein CE, Kumaran K, Cox V, Osmond C, Barker DJ and Hales CN: Size at birth, maternal weight, and type 2 diabetes in South India. Diabet Med 15: 220-227, 1998. 
38. Forsen T, Eriksson J, Tuomilehto J, Reunanen A, Osmond C and Barker D: The fetal and childhood growth of persons who develop type 2 diabetes. Ann Intern Med 133: 176-182, 2000.

39. Eriksson M, Wallander MA, Krakau I, Wedel H and Svardsudd K: Birth weight and cardiovascular risk factors in a cohort followed until 80 years of age: The study of men born in 1913. J Intern Med 255: 236-246, 2004.

40. Kaijser M, Bonamy AK, Akre O, Cnattingius S, Granath F, Norman M and Ekbom A: Perinatal risk factors for diabetes in later life. Diabetes 58: 523-526, 2009.

41. Bernardi JR, Goldani MZ, Pinheiro TV, Guimaraes LSP, Bettiol H, da Silva AAM and Barbieri MA: Gender and social mobility modify the effect of birth weight on total and central obesity. Nutr J 16: 38, 2017.

42. Au Yeung SL, Lin SL, Li AM and Schooling CM: Birth weight and risk of ischemic heart disease: A Mendelian randomization study. Sci Rep 6: 38420, 2016.

43. Dong YH, Zou ZY, Yang ZP, Wang ZH, Jing J, Luo JY, Zhang X, Luo CY, Wang H, Zhao HP, et al: Association between high birth weight and hypertension in children and adolescents: A cross-sectional study in China. J Hum Hypertens, 2017.

44. Lithell HO, McKeigue PM, Berglund L, Mohsen R, Lithell UB and Leon DA: Relation of size at birth to non-insulin dependent diabetes and insulin concentrations in men aged 50-60 years. BMJ (Clinical research ed) 312: 406-410, 1996.

45. Milovanovic I, Njuieyon F, Deghmoun S, Chevenne D, Levy-Marchal C and Beltrand J: SGA children with moderate catch-up growth are showing the impaired insulin secretion at the age of 4. PLoS One 9: e100337, 2014.

46. James-Todd TM, Karumanchi SA, Hibert EL, Mason SM, Vadnais MA, Hu FB and Rich-Edwards JW: Gestational age, infant birth weight, and subsequent risk of type 2 diabetes in mothers: Nurses' health study II. Prev Chronic Dis 10: E156, 2013.

47. Lawlor DA, Davey Smith G and Ebrahim S: Birth weight of offspring and insulin resistance in late adulthood: Cross sectional survey. BMJ (Clinical research ed) 325: 359, 2002.

48. Yajnik CS: Early life origins of insulin resistance and type 2 diabetes in India and other Asian countries. J Nutr 134: 205-210, 2004.

49. Mi J, Law C, Zhang KL, Osmond C, Stein C and Barker D: Effects of infant birth weight and maternal body mass index in pregnancy on components of the insulin resistance syndrome in China. Ann Intern Med 132: 253-260, 2000.
50. Osmond $\mathrm{C}$ and Barker DJ: Fetal, infant, and childhood growth are predictors of coronary heart disease, diabetes, and hypertension in adult men and women. Environ Health Perspect 108 (Suppl 3): S545-S553, 2000

51. Eriksson JG, Forsen TJ, Osmond C and Barker DJ: Pathways of infant and childhood growth that lead to type 2 diabetes. Diabetes Care 26: 3006-3010, 2003.

52. Kajantie E, Osmond C, Barker DJ and Eriksson JG: Preterm birth-a risk factor for type 2 diabetes? The Helsinki birth cohort study. Diabetes care 33: 2623-2625, 2010.

53. Phillips DI, Hirst S, Clark PM, Hales CN and Osmond C: Fetal growth and insulin secretion in adult life. Diabetologia 37 592-596, 1994

54. Mortensen B, Hingst JR, Frederiksen N, Hansen RW, Christiansen CS, Iversen N, Friedrichsen M, Birk JB, Pilegaard H, Hellsten Y, et al: Effect of birth weight and 12 weeks of exercise training on exercise-induced AMPK signaling in human skeletal muscle. Am J Physiol Endocrinol Metab 304: E1379-E1390, 2013.

55. Taylor DJ, Thompson CH, Kemp GJ, Barnes PR, Sanderson AL, Radda GK and Phillips DI: A relationship between impaired fetal growth and reduced muscle glycolysis revealed by $31 \mathrm{P}$ magnetic resonance spectroscopy. Diabetologia 38: 1205-1212, 1995.

56. Ivorra C, Garcia-Vicent C, Chaves FJ, Monleon D, Morales JM and Lurbe E: Metabolomic profiling in blood from umbilical cords of low birth weight newborns. J Transl Med 10: 142, 2012.

57. von Bonsdorff MB, Muller M, Aspelund T, Garcia M Eiriksdottir G, Rantanen T, Gunnarsdottir I, Birgisdottir BE, Thorsdottir I, Sigurdsson G, et al: Persistence of the effect of birth size on dysglycaemia and type 2 diabetes in old age: AGES-Reykjavik study. Age (Dordr) 35: 1401-1409, 2013.

58. Mooorthi MMS, Nadesan B, Ramalingam E and Thirumalaikumarasamy S: A study of maternal factors influencing very low birth weight babies. Int J Contemp Pediatr 4: 1173-1178, 2017.

59. Stocker C, O'Dowd J, Morton NM, Wargent E, Sennitt MV, Hislop D, Glund S, Seckl JR, Arch JR and Cawthorne MA: Modulation of susceptibility to weight gain and insulin resistance in low birth weight rats by treatment of their mothers with leptin during pregnancy and lactation. Int J Obes Relat Metab Disord 28: 129-136, 2004. 